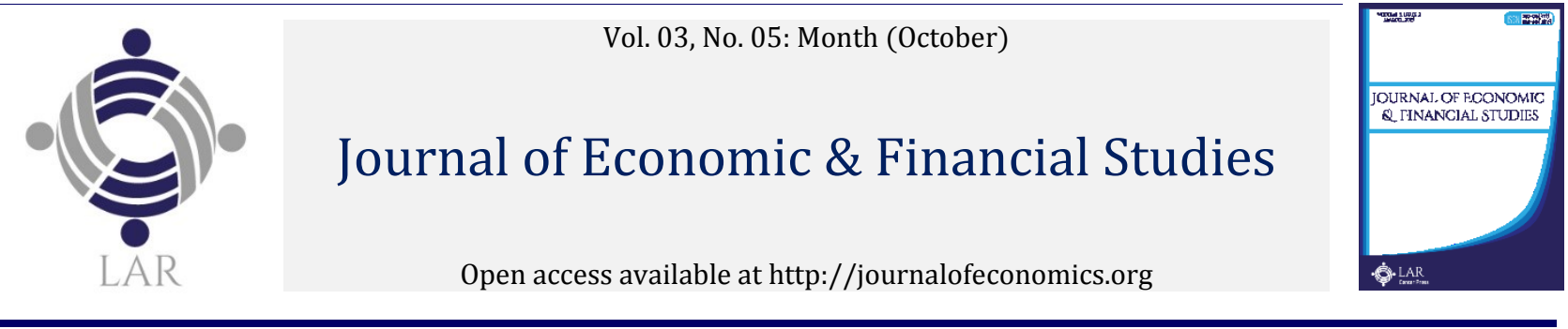

\title{
When the reaper becomes a salesman: The influence of terror management on product preferences ${ }^{1}$
}

\author{
Tom van Bommela ${ }^{a}$, Cormac 0’Dwyer, Tim W. M. Zuidgeest ${ }^{a}$, Fenna H. Poletiek ${ }^{b}$ \\ a AmsterBrand: Implicit Marketing Research. \\ ${ }^{\mathrm{b}}$ Leiden University, The Netherlands. \\ *Corresponding author's email address: t.vanbommel@amsterbrand.com
}

\section{A R T I C L E I N F O}

Received: 24-05-2015

Revised received: 26-07-2015

Accepted: 01-09-2015

Available online: 16-09-2015

Keywords:

Brand preferences;

Mortality salience;

Terror management theory.

\begin{abstract}
A B S T R A C T
The present research investigates how consumer choice is affected by Terror Management Theory's proposition of Mortality Salience increasing one's cultural worldview defense and self-esteem striving. The study builds empirically upon prior theorizing by Arndt, Solomon, Kasser and Sheldon (2004). During an experiment, we manipulated Mortality Salience and measured product preferences for conspicuousness and familiarity. Participants primed with death were more likely to choose conspicuous products, corroborating previous research of mortality salience raising materialistic tendencies. In addition, participants showed a tendency to prefer familiar brands. These results are in line with the Terror Management Theory framework.
\end{abstract}

JEL Classification:

M310, M370, M300.

(C) 2015 The Authors. This is an open access article under the terms of the Creative Commons Attribution License 4.0, which allows use, distribution and reproduction in any medium, provided the original work is properly cited.

DOI: http://dx.doi.org/10.18533/jefs.v3i05.121

\subsection{Introduction}

In their day-to-day lives, people are continuously reminded of the fragility of their own existence. This sometimes occurs in painfully blatant ways, such as when a loved one passes away or when a major tragedy hits global news, but oftentimes through subtle cues that affect us subconsciously - ranging from environmental wilderness (Koole \& Van den Berg, 2005) to regular television programming. Ever since the conceptualization of bounded rationality by Nobel laureate Herbert Simon (1967), emotional states and unconscious primes are found to be a ubiquitous force in many degrees of social behavior and decision making (Lerner, Li Valdeselo \& Kassam, 2015; Bargh, 2002). As Mortality Salience appears to be omnipresent in everyday life (Burke, Martens \& Faucher, 2010), research into how it affects consumer choice is a worthy endeavor in furthering decision science, policy and marketing.

The ability to become aware of one's mortality is considered to be uniquely human (Greenberg, Solomon \& Pyszczynski, 1997), and is capable of greatly influencing thoughts and behavior. Terror Management Theory (TMT) provides a comprehensive framework through which such Mortality Salience effects can be studied and explained. The theory is inspired by seminal anthropologist Ernest Becker (1973), whose tome The Denial of Death led social psychologists Greenberg, Pyszczynski and Solomon (1986) to formulate TMT. Since then, the

\footnotetext{
${ }^{1}$ This study was conducted in the context of the master's program Applied Cognitive Psychology at Leiden University.
} 
theory elicited a wealth of empirical research and theoretical discourse surrounding the concept of Mortality Salience.

According to TMT, the activation of death-related concepts temporarily increases one's concerns with mortality and the evanescence of life. In order to cope with such terrifying thoughts, humans arm themselves with several automatic defense mechanisms that allow them to restore their peace of mind. These mechanisms give rise to unique patterns in cognition, affect, behavior and motivation. The two most prominent defense mechanisms against terror, cited within the TMT literature, are (1) self-esteem striving, and (2) a greater adherence to one's cultural worldviews (Greenberg et al., 1997). A commonality between these tendencies is that they enrich life with symbolic meaning, which, according to TMT, serves as a potent anxiety buffer. Symbolic meaning is mainly shaped and transferred through cultural institutions. Consumption symbols such as brands and products may play a major role in one's self esteem, cultural worldviews and, therefore, how we deal with death.

The Terror Management framework has been applied to social psychological phenomena as diverse as stereotyping (Schimel, Simon, Greenberg, Pyszczynski, Solomon \& Waxmonsky, 1998), aggression (McCregor, Lieberman, Greenberg, Solomon, Arndt \& Simon, 1998), health behavior (Goldenberg \& Arndt, 2008), selfregulation (Ferraro, Shiv \& Bettman, 2005) and even reckless driving (Ben-Ari, Florian \& Mikulincer, 1999). However, it was not until the last decade that this wildly flowing stream of TMT research finally captured the attention of consumer researchers. Arndt, Solomon, Kasser and Sheldon (2004) were the first to construct a comprehensive overview of TMT's theoretical implications for consumer behavior. While compelling, these proposals are still hypothetical, inferred from general TMT research rather than the result of empirical investigation within the consumer realm itself. Although some first endeavors applied to the 'buying arena' have been made (Mandel \& Heine, 1999; Ferraro et al., 2005; Fransen, Fennis, Pruyn \& Das, 2008), its empirical underpinnings need further rigor to be useful in practice. With the present research, we aim to contribute to the empirical foundations of TMT in consumer behavior, by illuminating both new and existing ways in which Mortality Salience influences consumer preferences. These insights are not only beneficial for further theory construction, but are also of great value to marketers and policymakers, for instance when deciding the context in which to embed their messages.

\subsection{Terror management and conspicuous consumption}

The present study explores how Mortality Salience affects conspicuous consumption. Mandel \& Heine (1999) were first to investigate the effect of Mortality Salience on materialistic preferences. In their study, participants who were primed with death liked high-status products better than participants primed with negative affect. In a cross-cultural follow-up study, a similar pattern for Japanese consumers was found, although the effect was considerably weaker (Heine, Harihara \& Niiya, 2002). This may reflect the somewhat weaker association between consumption and self-esteem traditionally found in collectivistic cultures, even though their consumption of status goods is rapidly growing there as well (Wong \& Ahuvia, 1998).

It is important to note that the Mandel \& Heine (1999) study did not include a neutral control group, but compared a Mortality Salience prime with a negative affect prime. The authors justified this methodological decision with their objective to isolate 'death' from 'sad', as it is often debated whether negative affect is in essence the same as - or at least a side effect of - Mortality Salience (Greenberg, Simon, Harmon-Jones, Solomon, Pyszczynski, Lyon, 1995). Nonetheless, the lack of a neutral control group makes it harder to draw valuable practical implications from their research. It remains unclear whether Mortality Salience shapes consumer preferences any differently than a neutral everyday state-of-mind would. As individuals differ in the range of their daily emotional ebb and flow (Larsen \& Diener, 1987; Eaton \& Funder, 2001), a study comparing Mortality Salience with a baseline neutral emotional state is desirable. The present experiment therefore adopts a neutral control group, granting scholars and practitioners richer insights into how consumers primed with death think and act differently than they regularly would. As such, our first research question partly replicates the original Mandel \& Heine (1999) study, and valuably extends it. It strengthens the empirical underpinnings of TMT and sheds light on managerial pitfalls and opportunities in retail, marketing and advertising.

Drawing from TMT's theoretical premises, Arndt et al., (2004) argued that Mortality Salience may increase people's materialistic tendencies. As death-related thoughts fuel a motivational tendency towards self-esteem improvement, the authors theorized that conspicuous consumption (i.e., an increased preference towards materialistic products) should logically follow. High-status products have indeed been found to at least temporarily increase one's sense of self-worth (Sivanathan \& Pettit, 2010). And this effect ought to be more apparent in cultures that strongly associate consumption with status (e.g., western industrialized societies; Maheswaran \& Agrawal, 2004). 
Additionally, indirect evidence exists on Mortality Salience's facilitating effect on conspicuous consumption. Kasser and Sheldon (2000) found that death-related thoughts heightened people's expectations of their future income, as well as rendering them more greedy and sensitive to instant gratification and the attraction of shortterm gains in a resource-harvesting simulation. A later study by Cozzolino, Dawn Staples, Mayers and Samboceti (2004) applied an alternative resource game and found a similar pattern of results. As these findings are in line with TMT's predictions, we expect that consumers who are primed with death are more likely to prefer highstatus brands than neutrally primed consumers. Hence, the first hypothesis addressed in the present experiment is that Mortality Salience leads to more conspicuous brand choices, as compared to a neutral mood.

\section{H1: Mortality Salience increases conspicuous brand choices compared to a neutral mood.}

\subsection{Terror Management and preferences for familiar brands}

In addition to increasing materialistic product preferences, we expect Mortality Salience to exert another major influence on consumer decision making: temporarily raising preferences for brands and products that people have come to know and like. While this question has never been empirically studied, we propose that an increased reliance upon familiar products follows logically from TMT's premises.

According to TMT, the desire to reduce the anxiety and uncertainty triggered by thinking about death mediates Mortality Salience's effect on behavior (Greenberg et al., 1997). When death lingers top of mind, people appreciate safety, abhor danger (e.g., wilderness, as found by Koole \& Van den Berg, 2005) and rely more vigorously on familiar cultural symbolism. In an applied study, Landau, Greenberg, Solomon, Pyszczynski and Martens (2006) found that Mortality Salience led to a decrease in appreciation of modern art, unless the art had meaning by means of a title or a personal frame of reference. In a similar study conducted during George W. Bush's presidency, a death prime increased people's support for Bush as seating president, while decreasing support for his democratic opponent John Kerry (Landau et al., 2004). Together, these findings suggest that people show a greater appreciation of familiar concepts and maintain a more conservative worldview when primed with death.

To our knowledge, no research directly touches upon the issue of (un)familiar brand choice within the TMT domain. However, in somewhat related vein, Fransen et al., (2008) subtly manipulated mortality salience by means of a life insurance commercial and found a subsequent increased preference for domestic products over foreign ones (note that foreign does not equal unknown). On a theoretical level, Mandel and Heine (1999) briefly addressed the issue of novelty aversion when discussing future research directions. Interestingly, they propose two feasible but contradictory hypotheses regarding Mortality Salience's influence on brand preference. On the one hand, their anxiety-reduction hypothesis states that overstimulation, which is associated with high anxiety, may lead to safe and familiar choices. On the other hand, when people feel 'the end is near', they may be more motivated to live a life filled with variety.

The present research takes a theoretical stance in favor of the first (i.e., anxiety-reduction) hypothesis, because Mortality Salience has been found to influence behavior largely without conscious awareness or deliberate thinking (Pyszczynski, Solomon \& Greenberg, 1999). Greenberg et al., (1997) even call terror management the unconscious and ongoing defense against the thoughts regarding our own mortality. A painfully intrusive thought such as 'the end is near' unlikely results from the subtle death primes people encounter every day (e.g., insurance commercials, media exposure of crime and violence). As such, we expect brand preferences to follow the defense mechanisms reducing anxiety (Greenberg et al., 1997). People who are primed with death, compared to neutral controls, are more likely to prefer the brands and products they already know, as our hypothesis predicts. Note that brand familiarity is likely to exert great influence on buying behavior regardless of mortality salience, as it helps to greatly cut down on time and effort as a choice heuristic at the point of purchase (Hoyer \& Brown, 1990). We expect this familiarity preference to become even more apparent when mortality is salient.

Thus, we hypothesize that Mortality Salience triggers an implicit tendency to reduce the anxiety associated with death-related thoughts, rather than an explicit rational choice to spend the rest of our life in a hedonistic way. Therefore, our second hypothesis predicts a stronger tendency to choose familiar products rather than unfamiliar ones when mortality is salient.

H2: Mortality Salience increases familiar brand choices compared to a neutral mood.

This paper will continue with an outline of the present experiment, a statistical analysis of the empirical data and a discussion of the results, theoretical contributions and policy implications. 


\subsection{Method}

36 Dutch participants (25 Female, mean age 29 years) complete an online survey by means of Qualtrics Survey Software. We adopt a simple single-factor, two-level experimental design. We randomly assign participants to either a death-prime or a control condition.

\subsection{Procedure}

In the instructions, participants read that they are taking part in a marketing survey regarding brand preferences. After the briefing, they answer some initial questions that will supposedly facilitate the researcher's understanding of the target market's values, attitudes and lifestyles. Within these decoy questions, we embed a death-prime. Next, participants complete a PANAS affect survey, followed by the actual choice-task consisting of fifteen pairs of products, presented randomly. During each pair, the participant selects which one of the two they preferred most. In order to minimize suspicion regarding the true purpose of the research, we also include mock pairs that show no clear distinction on either conspicuousness or familiarity.

\subsection{Manipulation and measures}

Participants in the death-primed condition receive the following instructions (put forward by Arndt et al., 2004): 1- Please describe briefly the emotions that the thought of your own death arouse in you.

2- Jot down, as specifically as you can, what you think will happen as you physically die.

We induce the control group with a common neutral mindset. Participants in this condition simply make a list of their daily activities. Many earlier TMT studies have implemented similar approaches to control groups (for an overview, see Greenberg et al., 1997).

After the manipulation, participants complete a short version of the Positive and Negative Affect Scale (Watson, Clark and Tellegen, 1988). This scale is primarily added to shift participants' conscious internal focus away from mortality. As Mortality Salience effects are thought to operate outside of conscious awareness, diverting attention is a common practice found among virtually all TMT research $(92.8 \%)$. The PANAS is also widely embraced because it is able to uncover unintended extraneous influences on affect caused by the death prime (PANAS is used by $47.7 \%$ of TMT research; Burke et al., 2010).

The dependent measure consists of the choice participants made at seven critical product pairs (out of a total of fifteen pairs). Each pair measures either preference for conspicuousness, familiar products or familiar brands. We include two pairs to measure conspicuous preference (e.g., Chanel snowboard vs. Ride snowboard), three pairs for unfamiliar brands (e.g., Grapple versus Jonagold apples) and two pairs for unfamiliar products by the same brand (e.g., a brand extension such as Golden Power versus Golden Power Juice). For each participant, we sum the amount of conspicuous choices (max. 2), choices for unfamiliar brands (max. 3) and choices for unfamiliar products within the same brand (max. 2). In addition to product choice, we asked our participants to rate each brand on a scale of 1 to 10 to enable further analysis. The product pairs are carefully selected in advance, based on a pre-test with eighteen participants. In order to ascertain that the perceived distinctions mirror our intended manipulations, we ask the pre-test participants to rate each product on the dimensions luxuriousness, familiarity and attractiveness. In order to rule out alternative explanations, we retain the brand pairs that are perceived as highly different on the dimension of interest (e.g., luxuriousness for Chanel vs. Ride) but that are still rated equally attractive in the pre-test.

\subsection{Results}

We perform independent T-tests to analyze differences in choice preferences across conditions. Four control participants and one death-prime participant are omitted from the analyses because they did not complete the survey.

\subsection{Conspicuous consumption}

Based on pre-test results, two equally attractive conspicuous-nonconspicuous brand pairs are retained. Participants who are primed with death preferred conspicuous products more often $(M=1.11, S D=.74)$ than do control participants $(M=.64, S D=.50), t(31)=2.15, p<.05$ (Figure 1$)$.

This finding corroborates our first hypothesis stating that Mortality Salience facilitates materialistic tendencies. It extends the original Mandel \& Heine (1999) study by demonstrating that Mortality Salience increases conspicuous choice not only compared to negatively valenced emotions, but also compared to a neutral mood. 
Figure 1: Participants primed with death showing a preference towards conspicuous products (mean number of conspicuous brand choices range $0-2$ ).

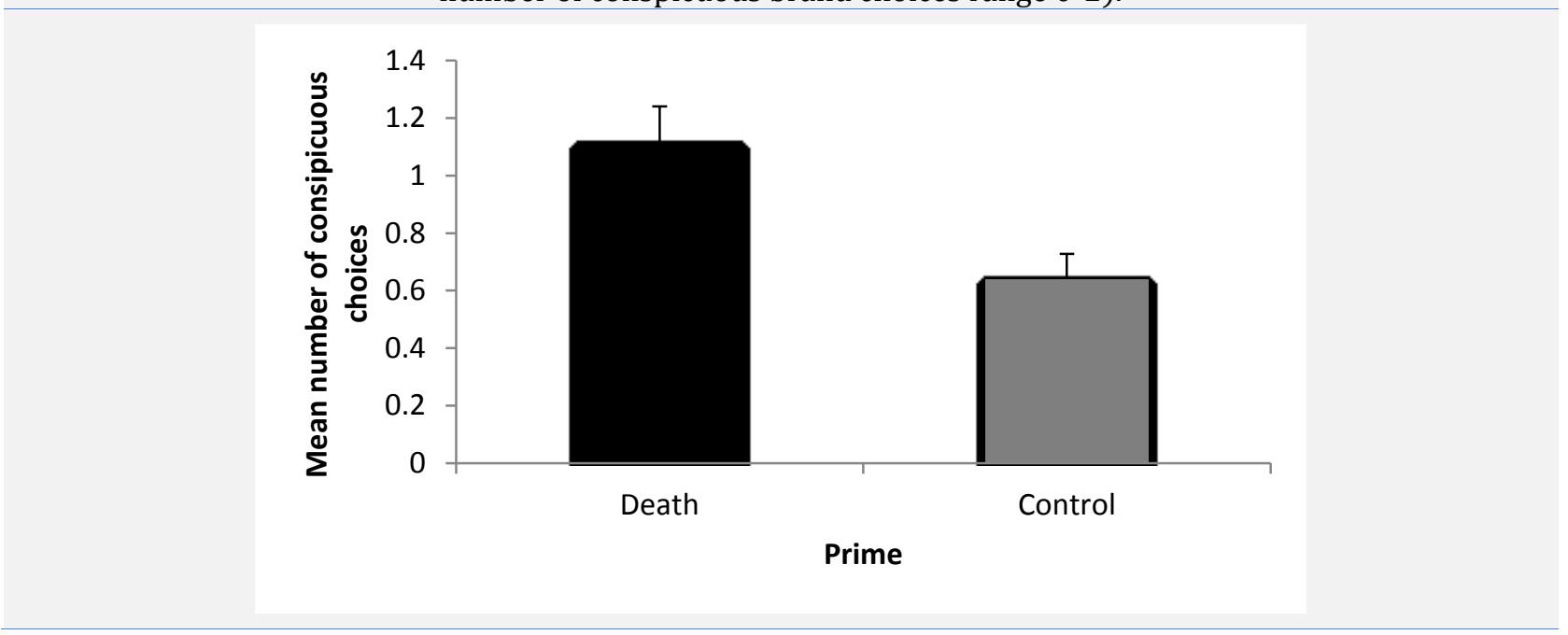

\subsection{Familiar products}

The familiar-unfamiliar pairs contain three product pairs of different brands, as well as two pairs containing an unfamiliar extension within the same brand. Choice for the latter was not influenced by our Mortality Salience prime, $t(31)=1.23, p=.83$. That is, participants do not favor a familiar product more than an unfamiliar one when it is made by the same (well-known) brand.

Figure 2. Participants primed with death showing a preference towards familiar brands (mean number of familiar brand choices range $0-3$ ).

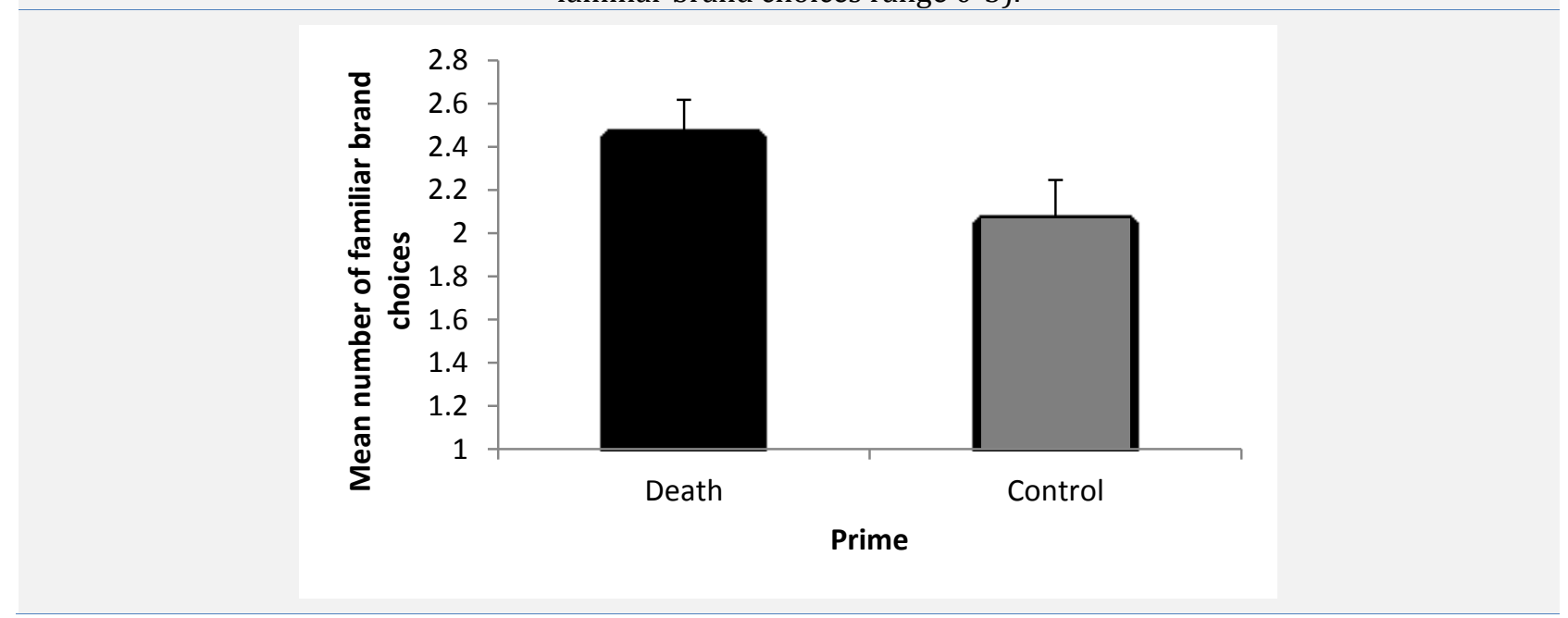

However, the pairs that contrasted familiar with unfamiliar brands did show a trend in the hypothesized direction, narrowly approaching significance, $t(31)=-1.26, p=.11$ (one-tailed). Participants primed with death tended to prefer familiar brands $(\mathrm{M}=2.47, S D=.84)$ more often than did control group participants $(\mathrm{M}=2.07, S D=1.00)$ (Figure 2).

Marginally significant, this finding is in the direction of our second hypothesis. It corroborates earlier findings that mortality salience increases preference for domestic products (Fransen et al., 2008), while further illuminating the symbolic role fulfilled by brands. Unfamiliar products are only disliked when launched by unfamiliar brands, which fits well with the recurring finding that Mortality Salience heightens the need for symbolic meaning and its effects diminish when this meaning comes to surface (Landau et al., 2006). Note that all participants clearly favor familiar brands, which is consistent with the well-documented consumer preference for familiarity (Park \& Lessig, 1981). Thus, the reason why the difference between priming conditions does not reach significance may be a ceiling effect and warrants further research. 


\subsection{Brand liking}

Further analysis of brand liking scores revealed an overall decrease in liking after a death prime $t(31)=-2.245, \mathrm{p}$ $<.05$. Participants primed with death liked brands less overall $(\mathrm{M}=4.92, \mathrm{SD}=1.15)$ than participants that received a neutral prime $(M=5.74, S D=.96)$. Mortality Salience appears to result in a general decrease in brand liking ratings.

Additional repeated measures ANOVAs revealed there were no further main effects or interactions with regard to liking ratings between conspicuous and non-conspicuous products, $\mathrm{F}(1,31)=.59, p=.48 ; \mathrm{F}(1,31)=.34, p=.56$. There was, however, a main effect of familiarity on liking scores, $\mathrm{F}(1,31)=14.66, p<.01$. Participants like familiar brands better $(M=6.02, S D=1.15)$ than unfamiliar brands $(M=4.7, S D=1.62)$. This corroborates research and market wisdom suggesting familiarity facilitates liking (Cialdini, 2009). There is no further interaction between prime and familiarity on liking score, $\mathrm{F}(1,31)=.51, p=.48$. Combined with the findings on product choice, this suggests Mortality Salience is capable of influencing decision making without necessarily altering liking.

\subsection{Discussions and recommendations}

\subsection{Mediation effects}

We argue that the need to repair self-esteem underlies the stronger materialistic tendencies following a death prime (proposed by Arndt et al., 2004), and an urge to reduce anxiety by adhering to one's cultural worldview (which is a general prediction of TMT; Greenberg et al., 1986) to underlie the relative preference towards familiar brands. Our experimental set-up strengthens the possibility that the preference for conspicuous products is mediated by a need to enhance self-esteem and a feeling of safeness, because of the additional preference for familiar rather than unfamiliar brands. The combined preference for conspicuous and familiar objects reveals a tendency towards self esteem striving and anxiety reduction, that helps to control the thoughts of death rather than a wish to enhance one's social status per se. These mediators - self esteem improvement and anxiety reduction - remain to be assessed in more detail in future experimental manipulations.

In addition to self-esteem enhancement, other mediators may play a role in shaping preferences for conspicuous goods under circumstances of Mortality Salience. For example, thoughts of death could induce a state of powerlessness, which in turn leads participants to "self-medicate" by choosing high-status products that restore their feelings of power (Rucker \& Galinsky, 2008). Future research could address this alternative possibility, by including a manipulation check for feelings of power after the product choice task as a hypothetical mediator.

Finally, for both hypotheses, it is possible that the effect of Mortality Salience may simply be mediated by negatively valenced mood resulting from thoughts about death. Because only our experimental condition incorporates the PANAS mood scale, differences in mood across conditions can not be directly analyzed. However, previous research on the role of affect in TMT provides evidence that rules out this alternative (Rosenblatt, Greenberg, Solomon, Lyon \& Pyszczynski, 1989; Mandel \& Heine, 1999). Especially when death primes are subtle and indirect, it is unlikely that emotional states are profoundly altered, if at all.

\subsection{Methodological discussion, applications and future research suggestions}

The present experiment adopts a binary choice methodology. This allows us to use real-world products that differ only in the variable of interest (i.e., conspicuousness and familiarity) - thereby balancing experimental and ecological validity. For each choice, we carefully selected brand pairs that were given roughly identical attractiveness ratings in our pilot study. This methodology comes with a number of limitations, though. Our aim for high ecological validity by using real brands in naturalistic web presentations makes it impossible to control for all variables. For example, visual differences or prior consumer knowledge may have impacted choice as well. In order to rule out this possibility, future research may consider using mock products that are specifically created for the experiment. In addition, binary choices may not reflect the complexity of real-life consumer behavior, where consideration sets typically comprise a larger number of brands and are continuously revised and thinned out before an actual purchase is made (Shocker, Ben-Akiva, Boccara \& Nedungadi, 1991). To add ecological validity, albeit at the expense of clarity of design, further research could employ a multiple choice set, asking participants to rate each of the included products on attractiveness.

As is the case in the majority of psychological experiments, participants made choices without having to experience real consequences. This can make their choices feel unnatural. One way to address this point would be the use of a willingness-to-pay (WTP) measure (Poletiek \& Stolker, 2004), where participants indicate the maximum price they would be willing to give in exchange for each product. Nonetheless, based on previous 
research showing that people who are primed with death develop higher expectations about their future income (Kasser and Sheldon, 2000), it could be argued that the same process causes them to bid substantially higher to acquire conspicuous products compared to control participants. A different approach to overcoming traditional experimental limitations would be to observe Mortality Salience effects in naturalistic settings. For instance, by analyzing how consumption patterns change around tragic events (e.g., the terrorist attacks at September 11, the death of a well known celebrity). In addition, now web analytics are a common good among researchers and practitioners alike, software enables researchers to bridge subtle death primes with real purchase data from ecommerce websites. For instance, how would a news story about a plane crash affect an on-page ad for a luxury clothes brand?

Our findings grant marketing practitioners and policymakers richer insights into what drives consumer choice and several fruitful areas of application. The habit of smoking - and the task of persuading people not to - is one such area. Anti-smoking advertising campaigns and government warnings on cigarette packets usually focus on strengthening the association of smoking with mortality. However, as smoking is commonly associated with glamour and social status among adolescents (Barton, Chassin, Presson \& Sherman, 1982), the association of cigarettes and death - effectively making cigarettes a mortality prime - could paradoxically make people more likely to light a cigarette.

Another application of our data is consumers' preference for green or environmentally friendly products. Social marketers often use threatening images of dying polar bears, rising sea levels and natural disasters to motivate consumers to make more environmentally responsible choices. If these persuasion attempts function as a death prime, they may actually dissuade people from changing their behavior to choose for novel, more environmentally friendly products. And because most death cues do not capture focal attention, but instead influence behavior unconsciously (Pyszczynski et al., 1999), the effect of Mortality Salience on openness to new products is likely to be most pronounced for behavior occurring similarly unconscious, automatic and habitual (Wood \& Neal, 2009).

In similar vein, mortality Salience could also have an impact on the effectiveness of surprise in advertising and policy communication. Surprise occurs in reaction to unexpected stimuli, or those that deviate from the status quo (e.g., Kahneman \& Miller, 1986). Since Terror management theory suggests that people primed with death are more motivated to preserve their established cultural worldview, they may also be more sensitive to surprise and regard it more negatively.

In the realm of policymaking, Terror Management research illuminates several caveats as well as potential areas of application. While our results will make advertisers of well known or luxury brands eager to advertise the minute after a shocking news story, this would be bad timing for communication endeavors that challenge the receiver's existing worldviews. This includes many social marketing causes, progressive political parties or campaigns that address social problems such as racism, obesity or climate change. Terror Management Theory stresses the importance for policymakers to be mindful of the context in which their messages are embedded. A slightly gruesome thriller may be just enough for a politically liberal message during the commercial break to meet blind resistance.

On the other hand, policy communication that addresses the feeling of local or national community may benefit from Mortality Salience. The motivation to reduce anxiety may make receivers particularly receptive towards causes that enhance their sense of self and culture. An example of a campaign appealing to local sentiment is the anti-littering campaign 'Don't Mess with Texas', created by The Texas Department of Transportation.

\subsection{Conclusion}

The present results provide evidence that, when the accessibility of thoughts about death is high, people increase their likelihood of choosing conspicuous over non-conspicuous brands and familiar over unfamiliar brands. Interestingly, this increased preference for what is familiar does not occur when an already famous brand releases an unfamiliar product under its own label. So while death-primed participants are relatively averse towards unfamiliar brands, they are not towards unfamiliar products per se (e.g., Red Bull introducing Red Bull Shots). This resonates with the recurrent Terror Management finding that cultural icons are often used to distance oneself from the fear of death (Greenberg et al., 1995), a role that may be naturally fulfilled by the symbolic power of brands (Elliott, 1994).

Thus, in line with Terror Management Theory, our data show that Mortality Salience guides consumer preferences towards products that may help them alleviate terror-producing thoughts. Firstly, it makes people more likely to choose high-status products, thereby protecting their self-esteem (Arndt et al., 2004). Secondly, the data suggest 
an increased appeal of familiar brands, which may be a sign of a greater adherence to one's established cultural worldviews and a stronger appeal of symbolism (Greenberg et al., 1986).

Overall, the present research has strengthened the empirical underpinnings of TMT's explanatory power for consumer behavior. It has validated earlier theorizing (Arndt et al., 2004) and sharpened previous empirical work (Mandel \& Heine, 1999; Fransen et al., 2008) as well as our global understanding of just how far the behavioral impact Mortality Salience can reach.

\section{References}

Arndt, J., Solomon, S., Kasser, T., \& Sheldon, K. M. (2004). The urge to splurge: A terror management account of materialism and consumer behavior. Journal of Consumer Psychology, 14(3), 198-212. http://www.sciencedirect.com/science/article/pii/S1057740804701485, http://dx.doi.org/10.1207/s15327663jcp1403_2, http://dx.doi.org/10.1207/s15327663jcp1403_5

Barton, J., Chassin, L., Presson, C. C., \& Sherman, S. J. (1982). Social image factors as motivators of smoking initiation in early and middle adolescence. Child Development, 1499-1511. http://www.ncbi.nlm.nih.gov/pubmed/7172778, http://dx.doi.org/10.2307/1130077

Bargh, J. A. (2002). Losing consciousness: Automatic influences on consumer judgment, behavior, and motivation. $\begin{array}{llll}\text { Journal of } & \text { consumer 280-285. }\end{array}$ http://www.sciencedirect.com/science/article/pii/S105774080570108X, http://dx.doi.org/10.1086/341577

Becker, E. (1973). The denial of death. New York: Free Press.

Ben-Ari, O. T., Florian, V., \& Mikulincer, M. (1999). The impact of mortality salience on reckless driving: a test of terror management mechanisms. Journal of personality and social psychology, 76(1), 35. http://www.ncbi.nlm.nih.gov/pubmed/9972551, http://dx.doi.org/10.1037/0022-3514.76.1.35

Burke, B. L., Martens, A., \& Faucher, E. H. (2010). Two decades of terror management theory: A meta-analysis of mortality salience research. Personality and Social Psychology Review, 14(2), 155-195. http://psr.sagepub.com/content/14/2/155.abstract, http://dx.doi.org/10.1177/1088868309352321

Cialdini, R. B. (2009). Influence: Science and practice (Vol. 4). Boston: Pearson Education.

Cozzolino, P. J., Staples, A. D., Meyers, L. S., \& Samboceti, J. (2004). Greed, death, and values: From terror management to transcendence management theory. Personality and Social Psychology Bulletin, 30(3), 278292. http://psp.sagepub.com/content/30/3/278.short, http://dx.doi.org/10.1177/0146167203260716

Eaton, L. G., \& Funder, D. C. (2001). Emotional experience in daily life: valence, variability, and rate of change. Emotion, 1(4), 413. http://psycnet.apa.org/journals/emo/1/4/413/, http://dx.doi.org/10.1037/15283542.1.4.413

Elliott, R. (1994). Exploring the symbolic meaning of brands. British Journal of Management, 5(s1), S13-S19. http://onlinelibrary.wiley.com/doi/10.1111/j.1467-8551.1994.tb00126.x/abstract

Ferraro, R., Shiv, B., \& Bettman, J. R. (2005). Let us eat and drink, for tomorrow we shall die: Effects of mortality salience and self-esteem on self-regulation in consumer choice. Journal of Consumer Research, 32(1), 65-75. http://www.gsb.stanford.edu/faculty-research/publications/let-us-eat-drink-tomorrow-we-shall-dieeffects-mortality-salience-self, http://dx.doi.org/10.1086/429601

Fransen, M. L., Fennis, B. M., Pruyn, A. T. H., \& Das, E. (2008). Rest in peace? Brand-induced mortality salience and consumer behavior. Journal of Business Research, 61(10), 1053-1061. http://www.sciencedirect.com/science/article/pii/S014829630700286X, http://dx.doi.org/10.1016/j.jbusres.2007.09.020

Goldenberg, J. L., \& Arndt, J. (2008). The implications of death for health: a terror management health model for behavioral health promotion. Psychological review, 115(4), 1032. http://www.ncbi.nlm.nih.gov/pubmed/18954213, http://dx.doi.org/10.1037/a0013326

Greenberg, J., Porteus, J., Simon, L., Pyszczynski, T., \& Solomon, S. (1995). Evidence of a terror management function of cultural icons: The effects of mortality salience on the inappropriate use of cherished cultural symbols. Personality and Social Psychology Bulletin, 21(11), 1221-1228. http://psp.sagepub.com/content/21/11/1221.short, http://dx.doi.org/10.1177/01461672952111010

Greenberg, J., Pyszczynski, T., \& Solomon, S. (1986). The causes and consequences of a need for self-esteem: A terror management theory. In Public self and private self (pp. 189-212). Springer New York. http://link.springer.com/chapter/10.1007\%2F978-1-4613-9564-5_10\#page-1, http://dx.doi.org/10.1007/978-14613-9564-5_10

Greenberg, J., Solomon, S., \& Pyszczynski, T. (1997). Terror management theory of self-esteem and cultural worldviews: Empirical assessments and conceptual refinements. Academic Press. http:// psycnet.apa.org/psycinfo/2003-00369-002, http://dx.doi.org/10.1016/s0065-2601(08)60016-7

Heine, S. J., Harihara, M., \& Niiya, Y. (2002). Terror management in Japan. Asian Journal of Social Psychology, 5(3), 187-196. http://onlinelibrary.wiley.com/doi/10.1111/1467-839X.00103/abstract 
Hoyer, W. D., \& Brown, S. P. (1990). Effects of brand awareness on choice for a common, repeat-purchase product. Journal of consumer research, 141-148. http://www.jstor.org/stable/2626806, http://dx.doi.org/10.1086/208544

Jeff, G. (1995). Testing alternative explanations for mortality salience effects: Terror management, value accessibility, or worrisome thoughts?. European Journal of Social Psychology, 25, 417-433. http://onlinelibrary.wiley.com/doi/10.1002/ejsp.2420250406/abstract

Kahneman, D., \& Miller, D. T. (1986). Norm theory: Comparing reality to its alternatives. Psychological review, 93(2), 136. http://psycnet.apa.org/psycinfo/1986-21899-001, http://dx.doi.org/10.1037/0033-295X.93.2.136

Kasser, T., \& Sheldon, K. M. (2000). Of wealth and death: Materialism, mortality salience, and consumption behavior. Psychological science, 11(4), 348-351. http://www.ncbi.nlm.nih.gov/pubmed/11273398, http://dx.doi.org/10.1111/1467-9280.00269

Koole, S. L., \& Van den Berg, A. E. (2005). Lost in the wilderness: terror management, action orientation, and nature evaluation. Journal of personality and social psychology, 88(6), 1014. http://www.ncbi.nlm.nih.gov/pubmed/15982119, http://dx.doi.org/10.1037/0022-3514.88.6.1014

Landau, M. J., Greenberg, J., Solomon, S., Pyszczynski, T., \& Martens, A. (2006). Windows into nothingness: Terror management, meaninglessness, and negative reactions to modern art. Journal of Personality and Social Psychology, 90(6), 879. http://psycnet.apa.org/journals/psp/90/6/879/, http://dx.doi.org/10.1037/00223514.90.6.879

Landau, M. J., Solomon, S., Greenberg, J., Cohen, F., Pyszczynski, T., Arndt, J., ... \& Cook, A. (2004). Deliver us from evil: The effects of mortality salience and reminders of 9/11 on support for President George W. Bush. Personality and Social Psychology Bulletin, 1136-1150. http://psp.sagepub.com/content/30/9/1136.short, http://dx.doi.org/10.1177/0146167204267988

Larsen, R. J., \& Diener, E. (1987). Affect intensity as an individual difference characteristic: A review. Journal of Research in personality, 21(1), 1-39. http://www.sciencedirect.com/science/article/pii/0092656687900237, http://dx.doi.org/10.1016/0092-6566(87)90023-7

Lerner, J. S., Li, Y., Valdesolo, P., \& Kassam, K. S. (2015). Emotion and decision making. Psychology, 66. http://www.annualreviews.org/eprint/vVKIPZU5r9dTCzbgdD3M/full/10.1146/annurev-psych-010213115043, http://dx.doi.org/10.1146/annurev-psych-010213-115043

Maheswaran, D., \& Agrawal, N. (2004). Motivational and cultural variations in mortality salience effects: Contemplations on terror management theory and consumer behavior. Journal of Consumer Psychology, 14(3), 213-218. $\quad$ http://www.sciencedirect.com/science/article/pii/S1057740804701497, http://dx.doi.org/10.1207/s15327663jcp1403_3

Mandel, N., \& Heine, S. J. (1999). Terror management and marketing: He who dies with the most toys wins. Advances in consumer research, 26, 527-532. http://www.acrwebsite.org/search/view-conferenceproceedings.aspx?Id=8314

McGregor, H. A., Lieberman, J. D., Greenberg, J., Solomon, S., Arndt, J., Simon, L., \& Pyszczynski, T. (1998). Terror management and aggression: evidence that mortality salience motivates aggression against worldviewthreatening others. Journal of personality and social psychology, 74(3), 590. http://psycnet.apa.org/journals/psp/74/3/590/, http://dx.doi.org/10.1037/0022-3514.74.3.590

Park, C. W., \& Lessig, V. P. (1981). Familiarity and its impact on consumer decision biases and heuristics. Journal of consumer research, 223-231. http://www.ncbi.nlm.nih.gov/pubmed/9523407, http://dx.doi.org/10.1086/208859

Poletiek, F.H., \& Stolker, C.J.J.M. (2004). Who decides the worth of an arm or leg? Assessing the monetary value of nonmonetary damage. In E. Kurz-Milcke \& G. Gigerenzer (Eds.), Experts in science and society (pp. 201-213). New York: Kluwer Academic/Plenum. http://link.springer.com/book/10.1007/b105826\#page=200, http://dx.doi.org/10.1007/0-306-47964-8_10

Pyszczynski, T., Greenberg, J., \& Solomon, S. (1999). A dual-process model of defense against conscious and unconscious death-related thoughts: an extension of terror management theory. Psychological review, 106(4), 835. http://www.ncbi.nlm.nih.gov/pubmed/10560330, http://dx.doi.org/10.1037/0033-295X.106.4.835

Rosenblatt, A., Greenberg, J., Solomon, S., Pyszczynski, T., \& Lyon, D. (1989). Evidence for terror management theory: I. The effects of mortality salience on reactions to those who violate or uphold cultural values. Journal of personality and social psychology, 57(4), 681. http://www.ncbi.nlm.nih.gov/pubmed/2795438, http://dx.doi.org/10.1037/0022-3514.57.4.681

Rucker, D. D., \& Galinsky, A. D. (2008). Desire to acquire: Powerlessness and compensatory consumption. Journal of Consumer Research, 35(2), 257-267. https://ideas.repec.org/a/ucp/jconrs/v35y2008i2p257-267.html, http://dx.doi.org/10.1086/588569

Schimel, J., Simon, L., Greenberg, J., Pyszczynski, T., Solomon, S., Waxmonsky, J., \& Arndt, J. (1999). Stereotypes and terror management: evidence that mortality salience enhances stereotypic thinking and preferences. Journal of personality and social psychology, 77(5), 905. http://www.ncbi.nlm.nih.gov/pubmed/10573872, http://dx.doi.org/10.1037/0022-3514.77.5.905

Shocker, A. D., Ben-Akiva, M., Boccara, B., \& Nedungadi, P. (1991). Consideration set influences on consumer decision-making and choice: Issues, models, and suggestions. Marketing letters, 2(3), $181-197$. http://dx.doi.org/10.1007/BF02404071 
Simon, H. A. (1967). Motivational and emotional controls of cognition. Psychological review, 74(1), 29. http://psycnet.apa.org/journals/rev/74/1/29/, http://dx.doi.org/10.1037/h0024127

Sivanathan, N., \& Pettit, N. C. (2010). Protecting the self through consumption: Status goods as affirmational commodities. Journal of Experimental Social Psychology, 46(3), 564-570. http://www.sciencedirect.com/science/article/pii/S0022103110000247, http://dx.doi.org/10.1016/j.jesp.2010.01.006

Watson, D., Clark, L. A., \& Tellegen, A. (1988). Development and validation of brief measures of positive and negative affect: the PANAS scales. Journal of personality and social psychology, 54(6), 1063. http://www.ncbi.nlm.nih.gov/pubmed/3397865, http://dx.doi.org/10.1037/0022-3514.54.6.1063

Wood, W., \& Neal, D. T. (2009). The habitual consumer. Journal of Consumer Psychology, 19(4), 579-592. http://www.sciencedirect.com/science/article/pii/S1057740809001065, http://dx.doi.org/10.1016/j.jcps.2009.08.003

Wong, N. Y., \& Ahuvia, A. C. (1998). Personal taste and family face: Luxury consumption in Confucian and Western societies. Psychology and Marketing, 15(5), $423-441$. http://onlinelibrary.wiley.com/doi/10.1002/\%28SICI\%291520-6793\%28199808\%2915:5\%3C423::AIDMAR2\%3E3.0.CO;2-9/abstract, http://dx.doi.org/10.1002/(SICI)1520-6793(199808)15:5<423::AIDMAR2>3.0.CO;2-9 